\title{
Third Order Universal Filter Using Single Operational Transresistance Amplifier
}

\author{
Mourina Ghosh, Sajal K. Paul, Rajiv Kumar Ranjan, and Ashish Ranjan \\ Department of Electronics Engineering, Indian School of Mines, Dhanbad 826004, India \\ Correspondence should be addressed to Sajal K. Paul; sajalkpaul@rediffmail.com
}

Received 4 September 2012; Revised 4 December 2012; Accepted 12 December 2012

Academic Editor: Paolo Colantonio

Copyright (C) 2013 Mourina Ghosh et al. This is an open access article distributed under the Creative Commons Attribution License, which permits unrestricted use, distribution, and reproduction in any medium, provided the original work is properly cited.

This paper proposes a multi-input single-output (MISO) third order voltage mode (VM) universal filter using only one operational transresistance amplifier (OTRA). The proposed circuit realizes low-pass, high-pass, all-pass, band-pass, and notch responses from the same topology. The PSPICE Simulation results using $0.5 \mu \mathrm{m}$ CMOS technology agree well with the theoretical design.

\section{Introduction}

Operational transresistance amplifier (OTRA) has emerged as an alternate current mode analog building block $[1,2]$ since it inherits all the advantages offered by other current mode building blocks such as current conveyor (CC) [3-6], operational transconductance amplifier (OTA) [7], current differencing buffered amplifier (CDBA) [8], differential voltage current conveyor (DVCC) [9]. The input terminals of OTRA are internally grounded, thereby eliminating parasitic capacitances at the input. OTRA has the advantages of a high slew rate and wide bandwidth. It is a high-gain current input voltage output device. Some analog filters using OTRA have been reported in [10-16] and references cited there in. It is well known that higher order analog filters using different kinds of active elements are of considerable interest, as they may be used for some special applications where sharp cut off is desirable and at the same time also useful to implement digital filters. Higher order filters can be obtained by various methods such as cascading lower order filter or state variable method or signal flow graph. Although OTRA based third order filters are reported in the literature [17-19], they all involve more that one OTRA.

In this work an attempt is made to propose a third order voltage mode (VM) universal filter employing single OTRA as an active element. All of the five filters, namely lowpass (LPF), highpass (HPF), allpass (APF), bandpass (BPF), notch $(\mathrm{NF})$, can be obtained from the same topology.

\section{Circuit Description}

The circuit symbol of an OTRA is illustrated in Figure 1. The characteristic equations of this element can be described as

$$
\left[\begin{array}{c}
V_{p} \\
V_{n} \\
V_{0}
\end{array}\right]=\left[\begin{array}{rrr}
0 & 0 & 0 \\
0 & 0 & 0 \\
R_{m} & -R_{m} & 0
\end{array}\right]\left[\begin{array}{c}
I_{p} \\
I_{n} \\
I_{0}
\end{array}\right] .
$$

A CMOS-based OTRA using $0.5 \mu \mathrm{m}$ CMOS technology is given in Figure 2 [2].

A generalized $n$th order filter topology using single OTRA is shown in Figure 3 [20]. The routine analysis gives a voltage transfer function as

$$
\frac{V_{\text {out }}(s)}{V_{\text {in }}(s)}=\frac{Y_{a}-Y_{b}}{Y_{c}-Y_{d}} .
$$

The proposed third order universal filter is obtained from Figure 3, if one considers $1 / Y_{a}=Z_{a}=R_{\mathrm{a} 1}\left\|1 / s C_{\mathrm{a} 1}\right\|\left(R_{\mathrm{a} 2}+\right.$ $\left.1 / s c_{\mathrm{a} 2}\right), 1 / Y_{b}=Z_{b}=1 / s C_{\mathrm{b} 1} \|\left(R_{b}+1 / s c_{\mathrm{b} 2}\right), 1 / Y_{c}=Z_{c}=$ $R_{c}\left\|1 / s C_{c}, 1 / Y_{d}=Z_{d}=R_{d}\right\| 1 / s C_{d}$ and splits the $Y_{a}$ terminal into three parts and $Y_{b}$ terminal into two parts as shown in Figure 4.

The routine analysis gives output voltage as

$$
V_{\text {out }}=\frac{N(s)}{D(s)}
$$




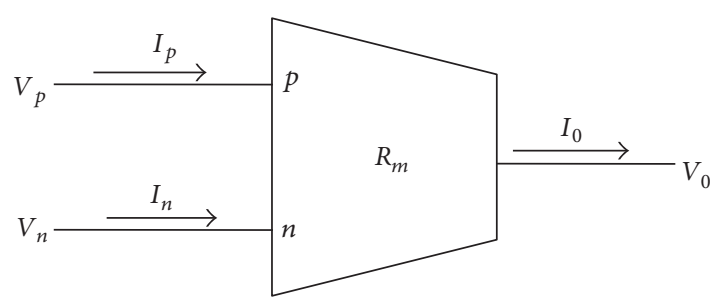

FIgURE 1: Block diagram of OTRA.

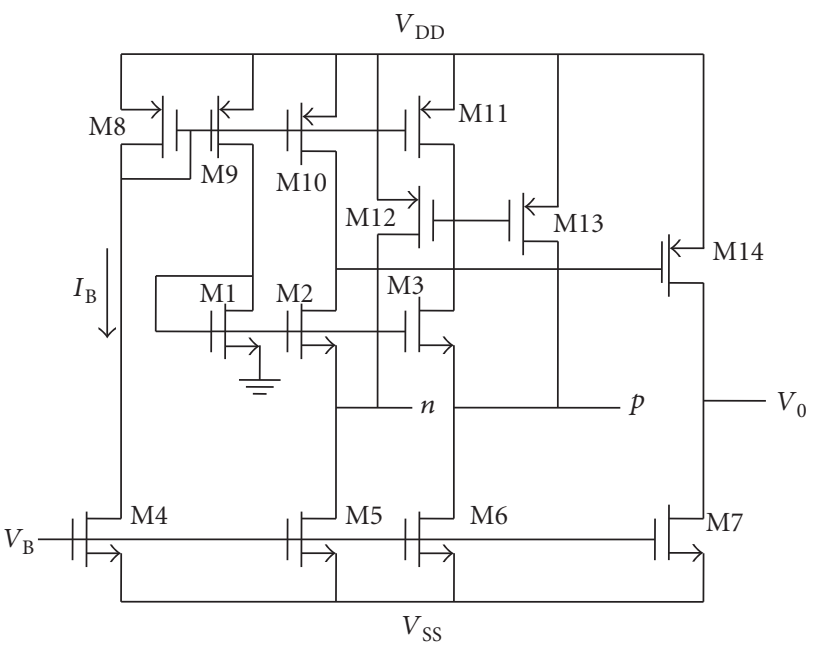

FIgURE 2: Internal circuit of OTRA [2].

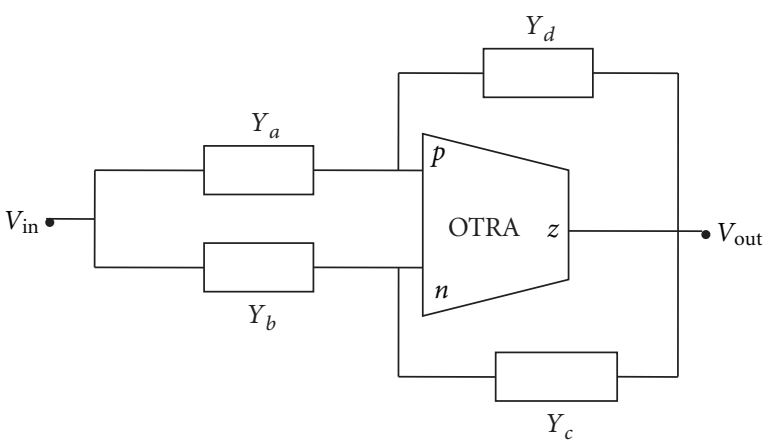

FIGURE 3: Generalized $n$th order filter.

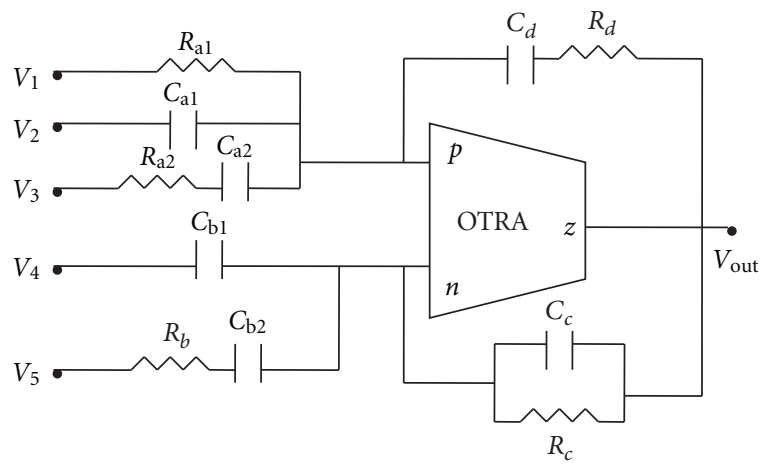

FIgURE 4: Proposed third order universal filter. where

$$
\begin{aligned}
& N(s)=R_{c}\left(1+s C_{d} R_{d}\right) \\
& \times\left\{\left(1+s C_{\mathrm{b} 2} R_{b}\right)\left(1+s C_{\mathrm{a} 2} R_{\mathrm{a} 2}\right) V_{1}\right. \\
& -s C_{\mathrm{a} 1} R_{\mathrm{a} 1}\left(1+s C_{\mathrm{b} 2} R_{b}\right)\left(1+s C_{\mathrm{a} 2} R_{\mathrm{a} 2}\right) V_{2} \\
& -s C_{\mathrm{a} 2} R_{\mathrm{a} 2}\left(1+s C_{\mathrm{b} 2} R_{b}\right) V_{3} \\
& -s C_{\mathrm{b} 1} R_{\mathrm{a} 1}\left(1+s C_{\mathrm{b} 2} R_{b}\right)\left(1+s C_{\mathrm{a} 2} R_{\mathrm{a} 2}\right) V_{4} \\
& \left.-s C_{\mathrm{b} 2} R_{\mathrm{a} 1}\left(1+s C_{\mathrm{a} 2} R_{c}\right) V_{5}\right\}, \\
& D(s)=R_{\mathrm{a} 1}\left(1+s C_{\mathrm{b} 2} R_{b}\right)\left(1+s C_{\mathrm{a} 2} R_{\mathrm{a} 2}\right) \\
& \times\left\{\left(1+s C_{c} R_{c}\right)\left(1+s C_{d} R_{d}\right)-s C_{d} R_{c}\right\} . \\
& \text { If } C_{\mathrm{a} 2} R_{\mathrm{a} 2}=C_{d} R_{d} \text {, then (4) modifies as } \\
& N(s)=R_{c} \\
& \times\left\{\left(1+s C_{\mathrm{b} 2} R_{b}\right)\left(1+s C_{\mathrm{a} 2} R_{\mathrm{a} 2}\right) V_{1}\right. \\
& -s C_{\mathrm{a} 1} R_{\mathrm{a} 1}\left(1+s C_{\mathrm{b} 2} R_{b}\right)\left(1+s C_{\mathrm{a} 2} R_{\mathrm{a} 2}\right) V_{2} \\
& -s C_{\mathrm{a} 2} R_{\mathrm{a} 2}\left(1+s C_{\mathrm{b} 2} R_{b}\right) V_{3} \\
& -s C_{\mathrm{b} 1} R_{\mathrm{a} 1}\left(1+s C_{\mathrm{b} 2} R_{b}\right)\left(1+s C_{\mathrm{a} 2} R_{\mathrm{a} 2}\right) V_{4} \\
& \left.-s C_{\mathrm{b} 2} R_{\mathrm{a} 1}\left(1+s C_{\mathrm{a} 2} R_{c}\right) V_{5}\right\}, \\
& D(s)=R_{\mathrm{a} 1}\left(1+s C_{\mathrm{b} 2} R_{b}\right) \\
& \times\left\{\left(1+s C_{c} R_{c}\right)\left(1+s C_{d} R_{d}\right)-s C_{d} R_{c}\right\} \\
& =R_{\mathrm{a} 1}\left(1+s C_{\mathrm{b} 2} R_{b}\right) \\
& \times\left\{s^{2} C_{c} R_{c} C_{d} R_{d}+s\left(C_{d} R_{d}+C_{c} R_{c}-C_{d} R_{c}\right)+1\right\} \\
& =R_{\mathrm{a} 1}\left[s^{3} C_{\mathrm{b} 2} R_{b} C_{c} R_{c} C_{d} R_{d}+s^{2}\right. \\
& \times\left\{C_{c} R_{c} C_{d} R_{d}+C_{\mathrm{b} 2} R_{b} C_{d} R_{d}\right. \\
& \left.+C_{\mathrm{b} 2} R_{b} C_{c} R_{c}-C_{\mathrm{b} 2} R_{b} C_{d} R_{c}\right\} \\
& \left.+s\left\{C_{\mathrm{b} 2} R_{b}+C_{c} R_{c}+C_{d} R_{d}-C_{d} R_{c}\right\}+1\right] .
\end{aligned}
$$

The specialization of (4), as shown in Tables 1 and 2, results the transfer function of low-pass filter (LPF), all-pass filter (APF), band-pass filter (BPF), and notch filter (NF) functions. Similarly high-pass (HPF) transfer function is obtained from (4) if $C_{\mathrm{b} 2} R_{b}=C_{d} R_{d}$.

The natural frequency and quality factor of the proposed circuit for LPF, APF, BPF, NF can be obtained as

$$
\begin{gathered}
\omega_{0}=\frac{1}{\sqrt[3]{C_{c} C_{d} C_{\mathrm{b} 2} R_{c} R_{b} R_{d}}}, \\
Q=\frac{\sqrt[3]{C_{d} C_{c} C_{\mathrm{b} 2} R_{c} R_{b} R_{d}}}{C_{c} R_{c}+C_{d} R_{d}-C_{d} R_{c}+C_{\mathrm{b} 2} R_{b}-\sqrt[3]{C_{c} C_{d} C_{\mathrm{b} 2} R_{c} R_{b} R_{d}}},
\end{gathered}
$$


TABLE 1: The availability of each filer response and corresponding selection of $V_{1}, V_{2}, V_{3}, V_{4}$, and $V_{5}$.

\begin{tabular}{lccccc}
\hline Filter response & \multicolumn{5}{c}{ Inputs $V_{\text {in }}$} \\
$V_{\text {out }}$ & $V_{1}$ & $V_{2}$ & $V_{3}$ & $V_{4}$ & $V_{5}$ \\
\hline Low pass filter (LPF) & 1 & 0 & 1 & 0 & 1 \\
High pass filter (HPF) & 0 & 1 & 1 & 0 & 1 \\
All pass filter (APF) & 1 & 0 & 1 & 1 & 1 \\
Band pass filter (BPF) & 0 & 0 & 1 & 0 & 1 \\
Notch filter (NF) & 1 & 1 & 1 & 0 & 1 \\
\hline
\end{tabular}

and for HPF as

$$
\begin{gathered}
\omega_{0}=\frac{1}{\sqrt[3]{C_{c} C_{d} C_{\mathrm{a} 2} R_{c} R_{\mathrm{a} 2} R_{d}}}, \\
Q=\frac{\sqrt[3]{C_{d} C_{c} C_{\mathrm{a} 2} R_{c} R_{\mathrm{a} 2} R_{d}}}{C_{c} R_{c}+C_{d} R_{d}-C_{d} R_{c}+C_{\mathrm{a} 2} R_{\mathrm{a} 2}-\sqrt[3]{C_{c} C_{d} C_{\mathrm{a} 2} R_{c} R_{\mathrm{a} 2} R_{d}}} .
\end{gathered}
$$

The sensitivity of $\omega_{0}$ with respect to passive elements may be expressed as

$$
S_{C_{c}}^{\omega_{0}}=S_{C_{d}}^{\omega_{0}}=S_{C_{\mathrm{b} 2}}^{\omega_{0}}=S_{C_{\mathrm{a} 2}}^{\omega_{0}}=S_{R_{c}}^{\omega_{0}}=S_{R_{b}}^{\omega_{0}}=S_{R_{d}}^{\omega_{0}}=S_{R_{\mathrm{a} 2}}^{\omega_{0}}=-\frac{1}{3} .
$$

It shows that the proposed circuit offers low sensitivity.

\section{Effect of Nonidealities of OTRA}

In this section the effect of finite transresistance gain $\left(R_{m}\right)$ on the output of the filter circuit is considered and for high frequency applications a passive compensation is employed in the same line as of reference $[10,11]$. Ideally the transresistance gain is assumed to approach infinity. However, practically $R_{m}$ is a frequency dependent finite value. Considering the single pole model for the transresistance gain, $R_{m}$ can be expressed as

$$
R_{m}(s)=\frac{R_{0}}{1+s / \omega_{0}},
$$

where $\omega_{0}$ is the pole frequency and $R_{0}$ is DC transresistance gain. In the case of high frequency application the transresistance gain $R_{m}(s)$ reduces to

$$
R_{m}(s)=\frac{1}{s C_{P}},
$$

where

$$
C_{P}=\frac{1}{R_{0} \omega_{0}} .
$$

Taking this effect into account the voltage transfer function (2) modifies to

$$
\frac{V_{\text {out }}(s)}{V_{\text {in }}(s)}=\frac{Y_{a}-Y_{b}}{Y_{c}-Y_{d}+s C_{p}},
$$

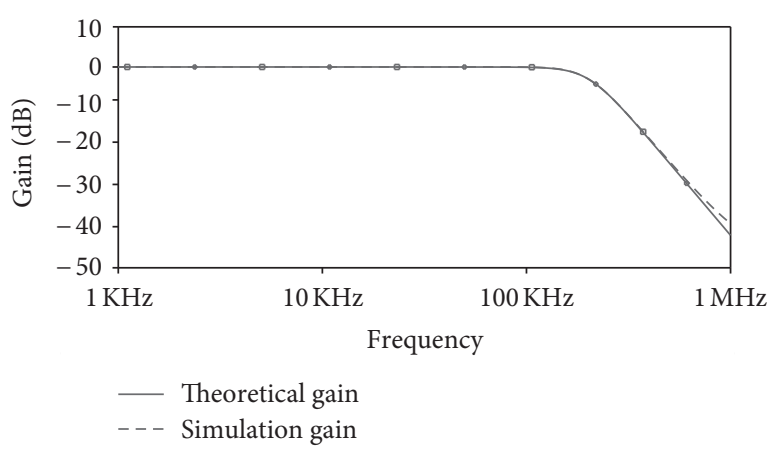

FIGURE 5: Frequency response of third order lowpass filter.

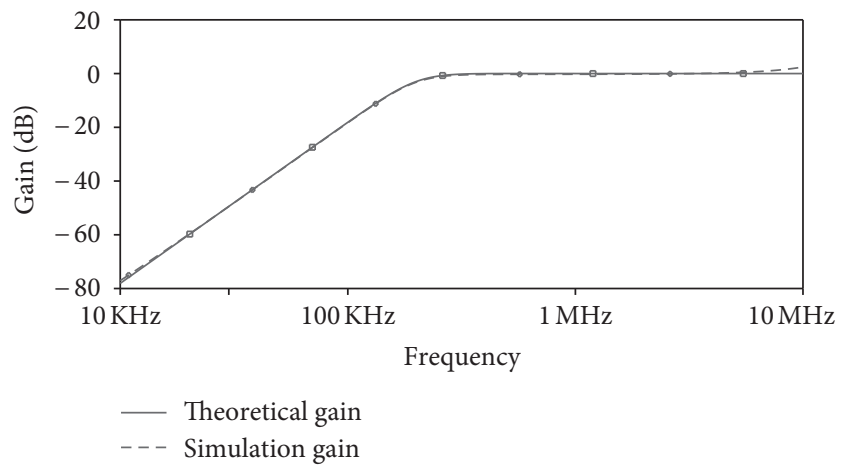

FIGURE 6: Frequency response of third order highpass filter.

where $s C_{p}$ is the uncompensated error term. In the case of high frequency applications, passive compensation method may be employed to account for error introduced in (2) which is given in (11). Inspection of circuit of Figure 4 and denominator of (11) indicates that error term $s C_{p}$ may be realized by connecting a capacitor $C_{P}$ in parallel to $Y_{c}$ or $C_{c}$ for passive compensation. In other words the value of $C_{c}$ may be decreased by $C_{P}$ to absorb the nonideality effect and thus achieving self-compensation. There is another nonideality due to parasitic resistances and capacitances. Since the input nodes in an OTRA are inherently grounded, the effect of parasites are negligible.

\section{Simulation Results}

The performance of the proposed universal filter is evaluated with CMOS implementation of OTRA as shown in Figure 2 [2], with DC power supply voltages $V_{\mathrm{DD}}=-V_{\mathrm{SS}}=1.5 \mathrm{~V}$ and bias voltage $V_{\mathrm{B}}=-0.5 \mathrm{~V}$. The simulations are performed using PSPICE based on $0.5 \mu \mathrm{m}$ MOSIS (AGILENT) CMOS technology parameters. Aspect ratios used for different transistors are same as [2].

The designed values of resistances and capacitances to obtain multifunction filter output for a cutoff frequency of $f_{0}=200 \mathrm{KHz}$ and quality factor of $\mathrm{Q}=1$ is shown in Table 3. The simulated frequency responses for gain of LPF, HPF, and BPF are shown in Figures 5, 6, and 7, respectively. It is observed that the simulated values closely 
TABLE 2: Condition of realization of each filter.

\begin{tabular}{ll}
\hline Filter response & Condition \\
\hline $\mathrm{LPF}$ & $R_{c} R_{\mathrm{a} 2}+R_{\mathrm{a} 1} R_{b}=R_{\mathrm{a} 2} R_{\mathrm{a} 1}, C_{\mathrm{a} 2} R_{\mathrm{a} 2}+C_{\mathrm{b} 2} R_{b}+C_{\mathrm{a} 2} R_{\mathrm{a} 1}=C_{\mathrm{b} 2} R_{\mathrm{a} 1}$ \\
$\mathrm{HPF}$ & $C_{\mathrm{a} 1}+C_{\mathrm{a} 2}=C_{\mathrm{b} 2}, C_{\mathrm{a} 1} C_{\mathrm{a} 2} R_{\mathrm{a} 2}+C_{\mathrm{a} 1} C_{\mathrm{b} 2} R_{b}+C_{\mathrm{a} 2} C_{\mathrm{b} 2} R_{b}=C_{\mathrm{b} 2} C_{\mathrm{a} 2} R_{\mathrm{a} 2}$ \\
$\mathrm{APF}$ & $C_{\mathrm{b} 1} R_{\mathrm{a} 1}=C_{c} R_{c},-\left(C_{\mathrm{a} 2} R_{\mathrm{a} 2}+C_{\mathrm{b} 2} R_{b}+C_{\mathrm{a} 1} R_{\mathrm{a} 1}-C_{\mathrm{b} 1} R_{\mathrm{a} 1}-C_{\mathrm{b} 2} R_{\mathrm{a} 1}\right)=C_{d} R_{d}+C_{c} R_{c}+C_{d} R_{c}+C_{\mathrm{b} 2} R_{b}, C_{\mathrm{b} 2} R_{b} C_{\mathrm{a} 2} R_{\mathrm{a} 2}+$ \\
$\mathrm{BPF}$ & $C_{\mathrm{a} 2} R_{\mathrm{a} 1} C_{\mathrm{b} 2} R_{b}-C_{\mathrm{b} 1} R_{\mathrm{a} 1} C_{\mathrm{a} 2} R_{\mathrm{a} 2}-C_{\mathrm{b} 1} R_{\mathrm{a} 1} C_{\mathrm{a} 2} R_{b}=C_{c} R_{c} C_{d} R_{d}+C_{\mathrm{b} 2} R_{b} C_{d} R_{d}+C_{\mathrm{b} 2} R_{b} C_{c} R_{c}-C_{\mathrm{b} 2} R_{b} C_{d} R_{c}$ \\
& $C_{\mathrm{a} 2}=C_{\mathrm{b} 2}$ \\
$\mathrm{NF}$ & $C_{\mathrm{a} 1} R_{\mathrm{a} 1}=C_{c} R_{c}, C_{d} R_{d}+C_{\mathrm{b} 2} R_{b}+C_{c} R_{c}-C_{d} R_{c}=C_{\mathrm{a} 2} R_{\mathrm{a} 2}+C_{\mathrm{b} 2} R_{b}+C_{\mathrm{a} 1} R_{\mathrm{a} 1}+C_{\mathrm{a} 2} R_{\mathrm{a} 1}-C_{\mathrm{b} 2} R_{\mathrm{a} 1}, C_{\mathrm{b} 2} R_{b} C_{\mathrm{a} 2} R_{\mathrm{a} 2}+C_{\mathrm{a} 1} R_{\mathrm{a} 1} C_{\mathrm{a} 2} R_{\mathrm{a} 2}+$ \\
\hline
\end{tabular}

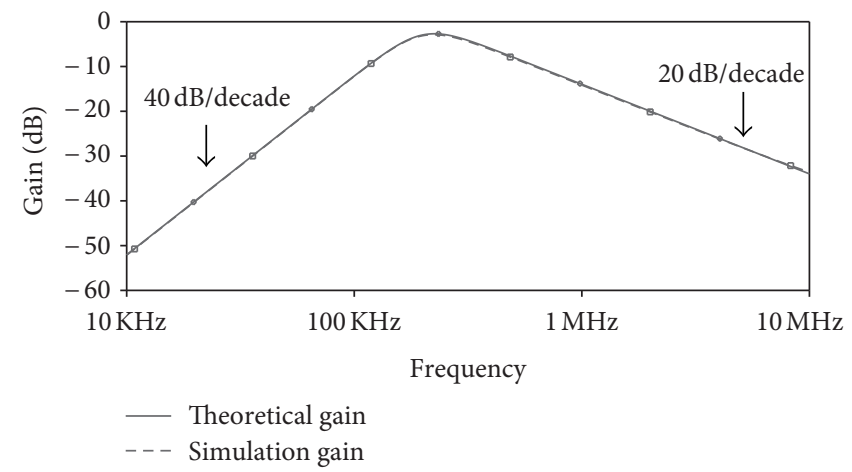

FIgURE 7: Frequency response of third order unsymmetrical bandpass filter.

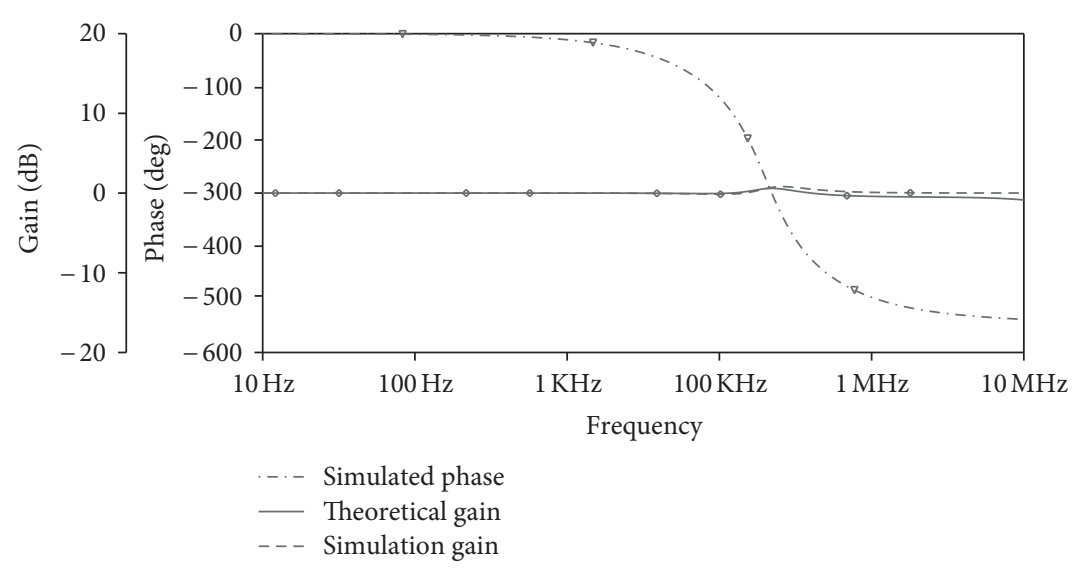

FIGURE 8: Frequency response of third order allpass filter.

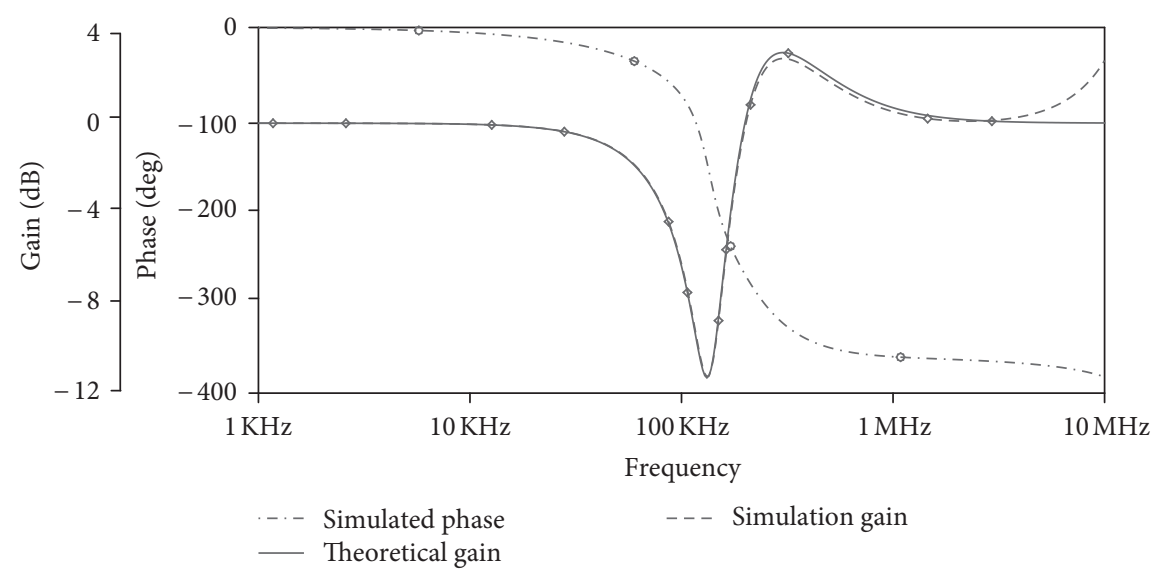

FIGURE 9: Frequency response of third order unsymmetrical notch filter. 
TABLE 3: Designed values of passive components used for VM third order filters.

\begin{tabular}{lccccccccccc}
\hline \multirow{2}{*}{ Filter response } & \multicolumn{10}{c}{ Component values } \\
& $R_{\mathrm{a} 1}(\mathrm{k} \Omega)$ & $C_{\mathrm{a} 1}(\mathrm{pF})$ & $R_{\mathrm{a} 2}(\mathrm{k} \Omega)$ & $C_{\mathrm{a} 2}(\mathrm{pF})$ & $C_{\mathrm{b} 1}(\mathrm{pF})$ & $R_{b}(\mathrm{k} \Omega)$ & $C_{\mathrm{b} 2}(\mathrm{pF})$ & $R_{c}(\mathrm{k} \Omega)$ & $C_{c}(\mathrm{pF})$ & $R_{d}(\mathrm{k} \Omega)$ & $C_{d}(\mathrm{pF})$ \\
\hline $\mathrm{LPF}$ & 200 & - & 200 & 1.99 & - & 100 & 7.96 & 200 & 7.96 & 66.66 & 5.97 \\
$\mathrm{HPF}$ & - & 7.96 & 100 & 7.96 & - & 25 & 15.92 & 200 & 7.96 & 66.66 & 5.97 \\
$\mathrm{APF}$ & 200 & - & 9.52 & 41.79 & 7.96 & 16.66 & 47.76 & 200 & 7.96 & 66.66 & 5.97 \\
$\mathrm{BPF}$ & - & - & 50 & 7.96 & - & 100 & 7.96 & 200 & 7.96 & 66.66 & 5.97 \\
$\mathrm{NF}$ & 200 & 7.96 & 200 & 1.99 & - & 50 & 15.92 & 200 & 7.96 & 66.66 & 5.97 \\
\hline
\end{tabular}

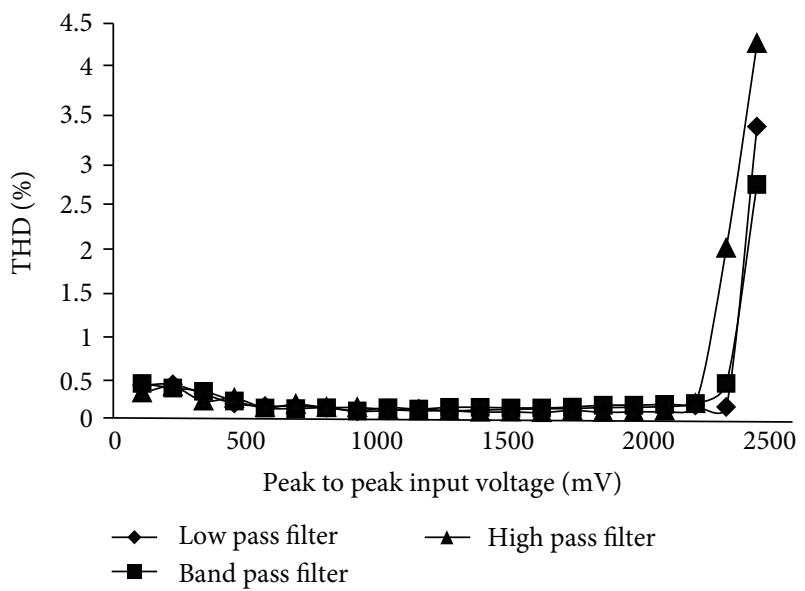

FIGURE 10: Variation of \%THD with respect to input voltage amplitude.

agree with the theoretical results. Figures 8 and 9 show the frequency responses for both gain and phase for APF and NF, respectively. It is observed that there is deviation of simulated gain at higher frequency for notch filter (NF). To judge the quality of the output, total harmonic distortion is obtained for low-pass, high-pass, and band-pass filter as shown in Figure 10. It is evident that the output distortion is very low and within $0.2 \%$ up to 2 volts. Hence it may be claimed that the output is of very good quality and dynamic range is high.

\section{Conclusion}

An OTRA based universal third order voltage mode filter is presented. Although a number of passive components matching is required, the proposed circuit offers the following advantageous features: (i) use of single OTRA, (ii) it has low output impedance, hence suitable for cascading, (iii) can implement all the five filter function such as lowpass, highpass, bandpass, allpass, and notch from same topology, (iv) moreover all the capacitors are grounded or virtually grounded, so suitable for monolithic IC implementation, and (v) effect of finite transresistance gain can be reduced by selfcompensation method, hence no additional elements needed.

\section{References}

[1] J. J. Chen, H. W. Tsao, and C. C. Chen, "Operational transresistance amplifier using CMOS technology," Electronics Letters, vol. 28, no. 22, pp. 2087-2088, 1992.
[2] H. Mostafa and A. M. Soliman, "A modified CMOS realization of the operational transresistance amplifier (OTRA)," Frequenz, vol. 60 , no. 3-4, pp. 70-76, 2006.

[3] J. W. Horng, "High-input impedance voltage-mode universal biquadratic filter using three plus-type CCIIs," IEEE Transactions on Circuits and Systems II, vol. 48, no. 10, pp. 996-997, 2001.

[4] J. W. Horng, "High-order current-mode and transimpedancemode universal filters with multiple-inputs and two-outputs using MOCCIIs," Radioengineering, vol. 18, no. 4, pp. 537-543, 2009.

[5] N. Pandey, S. K. Paul, and S. B. Jain, "A new electronically tunable current mode universal filter using MO-CCCII," Analog Integrated Circuits and Signal Processing, vol. 58, no. 2, pp. 171-178, 2009.

[6] W. Tangsrirat and W. Surakampontorn, "Electronically tunable current-mode universal filter employing only plus-type current-controlled conveyors and grounded capacitors," Circuits, Systems, and Signal Processing, vol. 25, no. 6, pp. 701-713, 2006.

[7] R. Šotner, J. Petržela, and J. Slezák, "Current-controlled currentmode universal biquad employing multi-output transconductors," Radioengineering, vol. 18, no. 3, pp. 285-294, 2009.

[8] A. U. Keskin and E. Hancioglu, "Current mode multifunction filter using two CDBAs," International Journal of Electronics and Communications, vol. 59, no. 8, pp. 495-498, 2005.

[9] S. Minaei and E. Yuce, "All-grounded passive elements voltagemode DVCC-based universal filters," Circuits, Systems, and Signal Processing, vol. 29, no. 2, pp. 295-309, 2010.

[10] K. N. Salama and A. M. Soliman, "CMOS operational transresistance amplifier for analog signal processing," Microelectronics Journal, vol. 30, no. 3, pp. 235-245, 1999.

[11] K. N. Salama and A. M. Soliman, "Universal filters using Operational Transresistance Amplifiers," International Journal of Electronics and Communication, vol. 53, no. 1, pp. 49-52, 1999.

[12] K. N. Salama and A. M. Soliman, "Active RC applications of the operational transresistance amplifier," Frequenz, vol. 54, no. 7-8, pp. 171-176, 2000.

[13] C. Cakir, U. Cam, and O. Cicekoglu, "Novel allpass filter configuration employing single OTRA," IEEE Transactions on Circuits and Systems II, vol. 52, no. 3, pp. 122-125, 2005.

[14] A. Gokcen, S. Kilinc, and U. Cam, "Fully integrated universal biquads using operational transresistance amplifiers with MOSC realization," Turkish Journal of Electrical Engineering and Computer Sciences, vol. 19, no. 3, pp. 363-372, 2011.

[15] U. Cam, F. Kacar, O. Cicekoglu, H. Kuntman, and A. Kuntman, "Novel grounded parallel immittance simulator topologies employing single OTRA," International Journal of Electronics and Communications, vol. 57, no. 4, pp. 287-290, 2003. 
[16] S. Kilinç and U. Çam, "Cascadable allpass and notch filters employing single operational transresistance amplifier," Computers and Electrical Engineering, vol. 31, no. 6, pp. 391-401, 2005.

[17] Y. S. Hwang, J. J. Chen, and W. T. Lee, "High-order linear transformation MOSFET-C filters using operational transresistance amplifiers," in Proceedings of IEEE International Symposium on Circuits and Systems (ISCAS '05), pp. 3275-3278, May 2005.

[18] J. J. Chen, H. W. Tsao, S. I. Liu, and W. Chiu, "Parasiticcapacitance-insensitive current-mode filters using operational transresistance amplifiers," IEE Proceedings: Circuits, Devices and Systems, vol. 142, no. 3, pp. 186-192, 1995.

[19] Y. S. Hwang, D. S. Wu, J. J. Chen, C. C. Shih, and W. S. Chou, "Realization of high-order OTRA-MOSFET-C active filters," Circuits, Systems, and Signal Processing, vol. 26, no. 2, pp. 281-291, 2007.

[20] C. Acar and H. Sedef, "Realization of nth-order current transfer function using current-differencing buffered amplifiers," International Journal of Electronics, vol. 90, no. 4, pp. 277-283, 2003. 

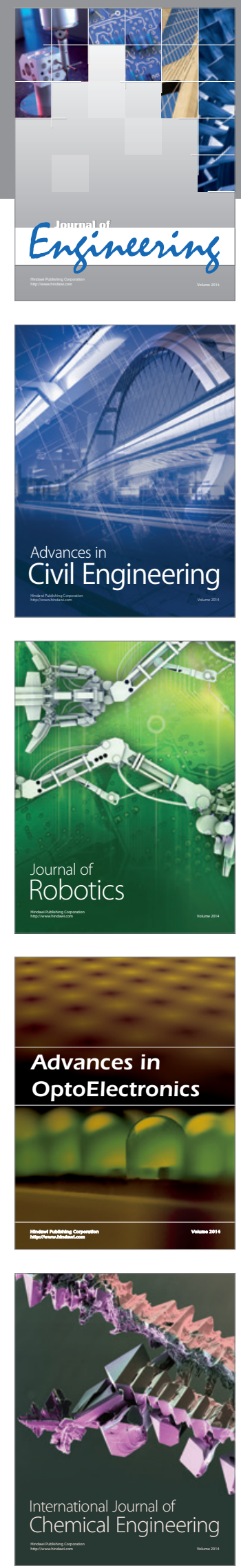

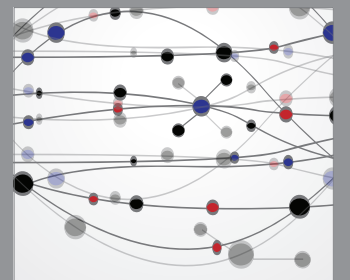

The Scientific World Journal
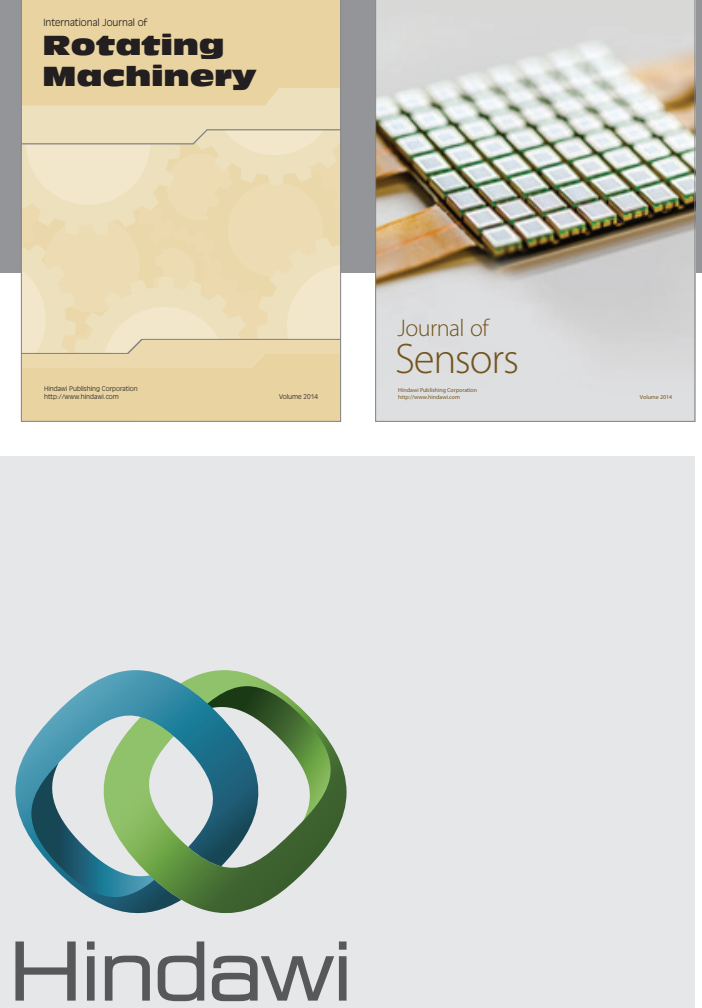

Submit your manuscripts at http://www.hindawi.com
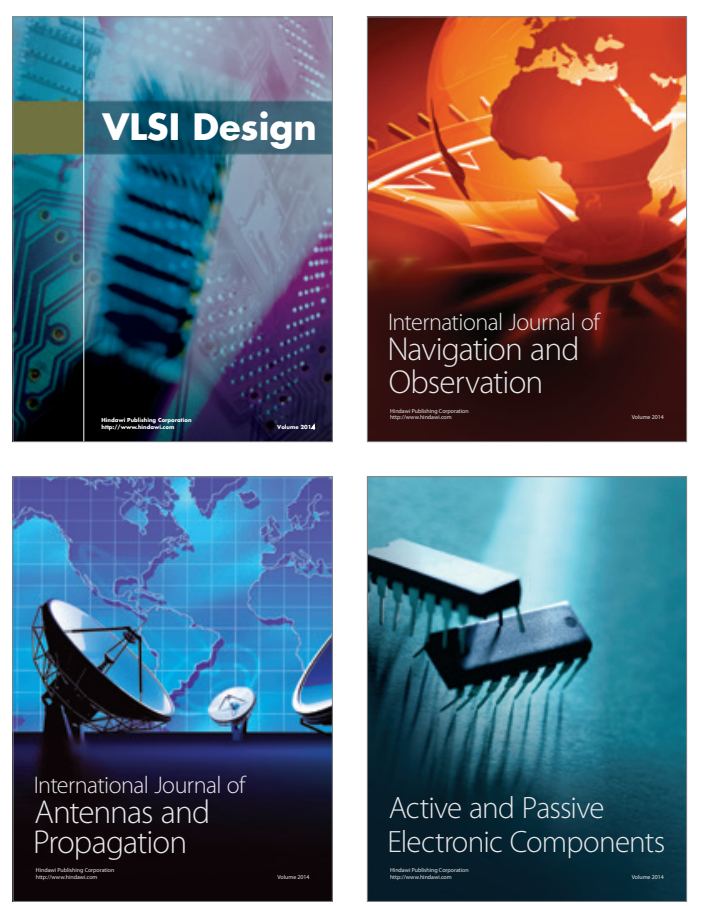
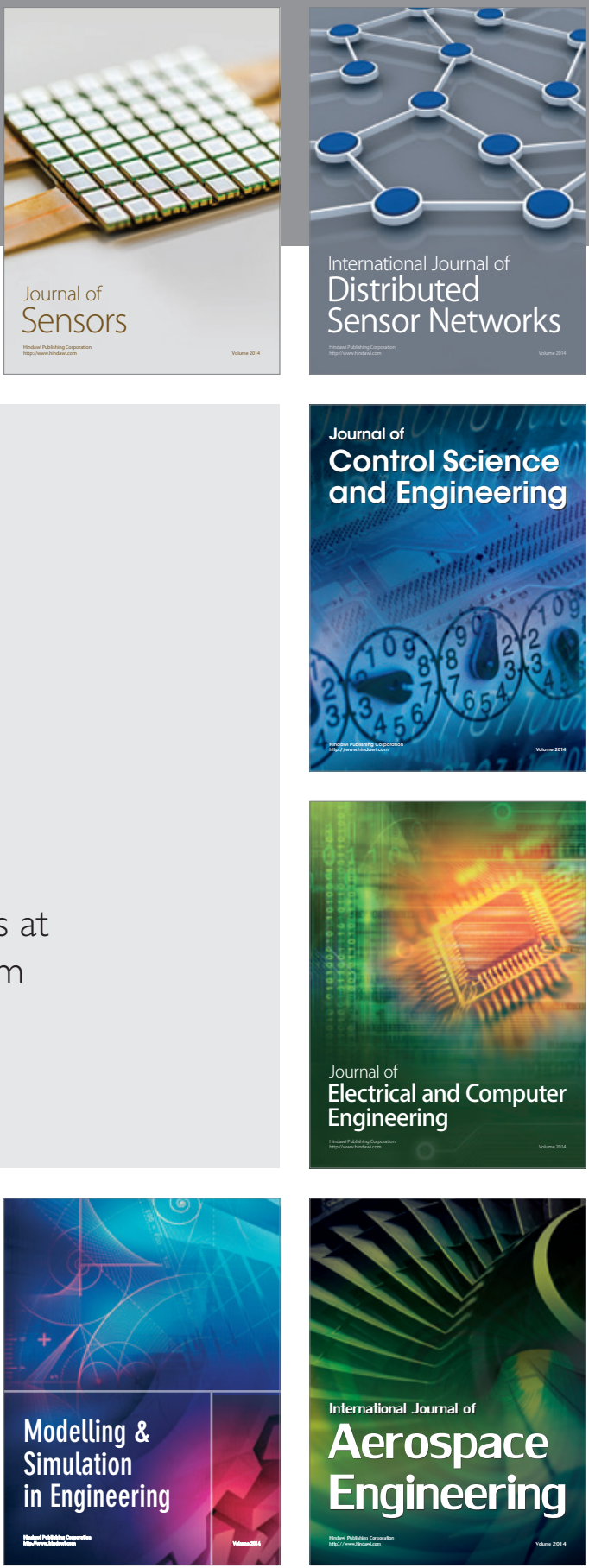

Journal of

Control Science

and Engineering
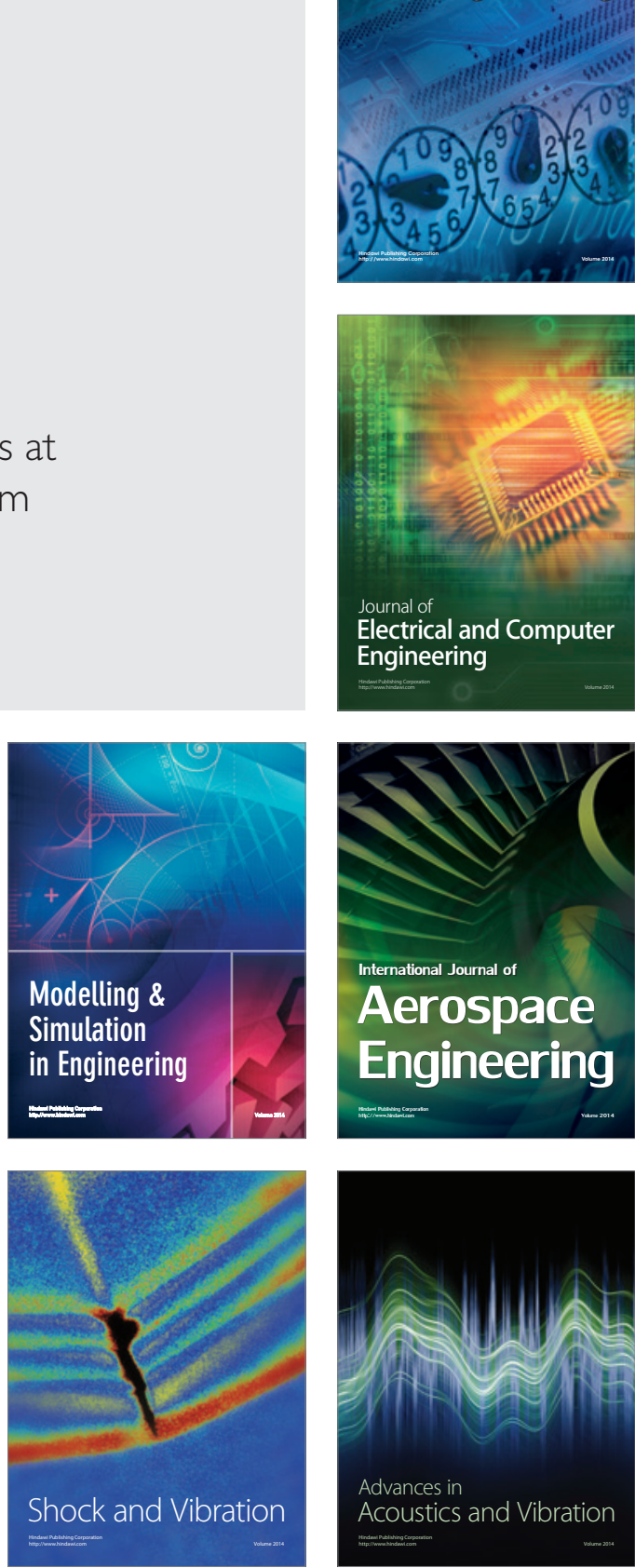